\title{
Coulisses
}

Revue de théâtre

19 | Hiver 1999

Varia

\section{Les Yeux rouges : de l'épopée à la mélopée}

\section{Lucile Garbagnati}

\section{(2) OpenEdition}

Journals

Édition électronique

URL : https://journals.openedition.org/coulisses/5425

DOI : 10.4000/coulisses.5425

ISSN : 2546-9460

\section{Éditeur}

Presses universitaires de Franche-Comté

\section{Édition imprimée}

Date de publication : 1 janvier 1999

Pagination : 17-19

ISBN : 2-913322-09-3

ISSN : $1150-594 X$

\section{Référence électronique}

Lucile Garbagnati, «Les Yeux rouges : de l'épopée à la mélopée », Coulisses [En ligne], 19| Hiver 1999, mis en ligne le 18 octobre 2019, consulté le 03 janvier 2022. URL : http://journals.openedition.org/ coulisses/5425; DOI : https://doi.org/10.4000/coulisses.5425

Ce document a été généré automatiquement le 3 janvier 2022

Coulisses 


\title{
Les Yeux rouges : de l'épopée à la mélopée
}

\author{
Lucile Garbagnati
}

«J'habitais Palente, j'ai diffusé et acheté les montres clandestines, j'ai rassuré des amis étrangers : Besançon n'était pas à feu et à sang, j'ai eu les yeux rougis des retombées des gaz

lacrymogènes... »

1 Les Yeux rouges $^{1}$ ? commande du Centre Dramatique de Franche-Comté auprès de Dominique Féret, connu pour avoir mis en scène, à partir de La Misère du Monde de Bourdieu, le témoignage d'Abbas, ouvrier algérien à la retraite qui racontait sa vie en France.

2 Le spectacle a été largement couvert par :

la critique nationale :

- Libération, 15 octobre 1998 : «Vingt-cinq ans après, la pièce Les yeux rouges met en scène les témoins d'une grève mythique. »;

- Le Monde, 21 octobre 1998 : «Vingt-cinq ans de la vie des « Lip » sur un plateau, mis en scène par Dominique Féret, les témoignages émouvants des ouvriers de la manufacture horlogère. ";

- Témoignage Chrétien, 22 octobre 1998 : « Témoignages citoyens, les Lip à nouveau en scène. » ; la critique régionale :

- L'est républicain, 15 octobre 1998 : «Les yeux rouges, dans l'intimité des « Lip ».;

- La terre de chez nous, 17 octobre 1998 : «L'avant et l'après Lip. ";

- L'impartial, 24 octobre 1998 : «Lip il y a 25 ans, Les yeux rouges en quête de mémoire. ».

3 Cette revue de presse nous a été aimablement fournie, à notre demande, par le CDN. Nous y ajouterons celle de L'Echo du Zinc de novembre 1998 qui titre :

«Les yeux roses. »

Initié à Belfort, baptisé à Palente, joué au CDN fin octobre, Les yeux rouges a déjà fait parler de lui nationalement. Plus proche de Karlin \& Laîné que de «Là-bas si j'y suis », mettant en scène les véritables interviews de quatre 
véritables Lip, ce bel essai ne nous a pas transformé. Il est dans l'heure du temps.

4 L'ensemble des articles rappelle les conditions de la production qui implique le CDN dans l'histoire locale, reconnaît « une mise en scène aussi minimaliste que saisissante, à l'opposition d'un numéro d'imitation » (Libération), célèbre la performance des acteurs : « ils ne sont pas confits dans la reproduction, mais dans l'invention de ce que peut être un "Lip" » (Le Monde). Mais de "l'affaire Lip», de l'espoir qu'elle a fait naître, de son utopie, des relations avec la situation actuelle, de son exemplarité célébrée ailleurs, dans de multiples ouvrages et articles, il n'est pas question.

5 Sur une trentaine d'interviews ( $L a$ terre de chez nous), le metteur en scène en a sélectionné quatre : trois femme, un homme. Trois ouvrières et Charles Piaget. Trois anonymes et le chef du mouvement.

6 Que dit cette parole réduite à la confidence? Elle dit le fil des jours : comment deux femmes jeunes, belles et désirables découvrent la vie, et l'assument : l'une à travers la découverte naïve du spectaculaire des meetings, la deuxième grâce à un nouveau rapport avec son chef de service; comment elles ont vieilli, en rencontrant l'autre, en osant un voyage avec des amis en Algérie, en assumant l'entretien d'un fils chômeur, en se lançant dans l'accueil bénévole de familles visitant des prisonniers de droit commun. La mélopée du féminin au quotidien : comment faire pour ne pas vivre et mourir inutile et seule ? On retrouve ici des interrogations propres à notre époque et à notre société, et sans doute plus spécialement aux femmes.

7 De l'histoire de Lip, de la leçon salutaire qui pourrait en être retirée? Rien. Quel rapport avec le chômage ? Quel rapport à la politique de concentration des capitaux ? Quel moyen d'action? Alors que le conflit a suscité une émotion et des réactions internationales, que le «hall » de l'usine était tapissé de télégrammes et de lettres de soutien, qu'est-ce qui a fait capoter la lutte? Quelle leçon, quels exemples tirer aujourd'hui, à une époque où le militantisme cherche des moyens pour redonner leur dignité aux exclus du travail ? où des associations comme AC, dont Piaget est d'ailleurs responsable, sont en recherche pour redonner l'espérance?

8 Les Yeux rouges donnent à plein dans ce climat de chacun pour soi. Les femmes qui nous sont données à voir et à entendre racontent un moment crucial de leur vie. Pour l'une, la mort de son amant en gardant par-devers soi son chagrin, car cet amour est clandestin. Pour l'autre, assumer un fils chômeur. Pour une troisième, trouver dans le bénévolat une sociabilité. Quoi de plus normal, voire tristement banal. Dans tous les cas, l'expérience de Lip apparaît comme un prétexte à une découverte qui aurait pu se faire dans d'autres circonstances, mais jamais comme une expérience fondamentale et unique. Ces femmes sont seules. On se demande comment ont réagi, à l'époque, le mari, la famille. Où se trouve l'expérience d'un conflit considéré comme historique?

9 Tout se passe comme si sur l'ensemble des témoignages, le metteur en scène avait choisi les plus neutres et les plus consensuels, les plus politiquement corrects, les moins dérangeants parce qu'ils mettent en jeu des personnes au quotidien et non ce qu'elles pourraient représenter. Lorsque C. Piaget s'interroge sur le bien-fondé de son action militante, c'est au nom du droit à une vie personnelle. Chacun est ému : est-il possible, quand on est militant et responsable syndical en lutte, de préserver un espace privé ? Au-delà du regret de n'avoir pas été l'époux attentif qu'il aurait pu être, c'est peut-être un changement de mentalités qui est entrevu avec « le partage des tâches ménagères »; 
mais qui, en revanche, assurera celle de responsable syndical ? Il semble que l'interview de Piaget tourne court. Comme si, dans un pareil contexte, il se retenait de s'exprimer sur les luttes passées et à venir ; on a l'impression d'une parole retenue.

Là se trouve, sans doute, une des limites du spectacle, sans vouloir contester la sincérité de l'intention, et y voir comme l'a dit une spectatrice outrée, « une méthode assez sioux pour écarter la véritable question de l'affaire Lip, à savoir le chômage ". À vouloir jouer le jeu de l'interview de l'authenticité individuelle, le metteur en scène sape celui de l'adhésion à un mouvement collectif, celui de la lutte pour un monde moins inégalitaire, plus " partageux ». Le choix des interviewes a privilégié une parole ferme, maitresse d'elle-même, où l'ambiguïté de la situation de questionné(e) est masquée par la maîtrise de la langue. Or, au lieu de dévoiler le non-dit, ce qui est tu par pudeur, par peur du ridicule, employer à contresens ou pis à contre-époque des "grands mots " comme fraternité, égalité, partage ou ce qui peut être senti comme un slogan du «travail pour tous », le choix des textes et leur juxtaposition procèdent par omission. Ils réduisent à une affaire individuelle une aventure collective humaine et sociale. Ils réduisent une sorte d'épopée à une mélopée des déçus de la vie, ils transforment le spectateur en un aliéné de l'histoire. Ce moment de l'Histoire, avec une majuscule, de la vie ouvrière et économique de notre région et de notre pays, aurait pu, en perpétuant une mémoire par l'éclat du théâtre, régénérer le désir de lutte, le refus de la fatalité. Il se borne à une succession d'anecdotes, de tranches de vie, de confessions intimistes d'où l'essentiel est exclu : les ouvriers ont refusé le chômage, ils ont acquis un statut vis-à-vis de la postérité, ils sont devenus les « Lip ».

11 En somme tout se passe comme si, au nom du théâtre du quotidien, le metteur en scène gommait les véritables enjeux d'un conflit qui a marqué l'histoire ouvrière, comme s'il refusait d'envisager avec les spectateurs la situation d'aujourd'hui : le chômage et les moyens de l'affronter.

12 Les Yeux rouges, titre énigmatique, fait tout simplement appel au dicton populaire: "Dans la vie, tu n'auras que tes yeux pour pleurer", bien loin de tout ce qui peut évoquer une lutte, quelle qu'elle soit. Même si Les Yeux rouges se veulent témoignage en direct d'une parole ouvrière, on est loin d'un «théâtre ouvrier », chargé d'histoire et porteur d'avenir. On ne peut s'empêcher de regretter l'explosion rageuse et vitaliste de Turrini avec Éléments moins performants ${ }^{2}$, de s'interroger avec regret sur ce qu'à partir d'un tel matériau, auraient créé Ariane Mnouchkine ou Armand Gatti. 
Agnès Guignard et Carlos Chahine dans Les Yeux rouges

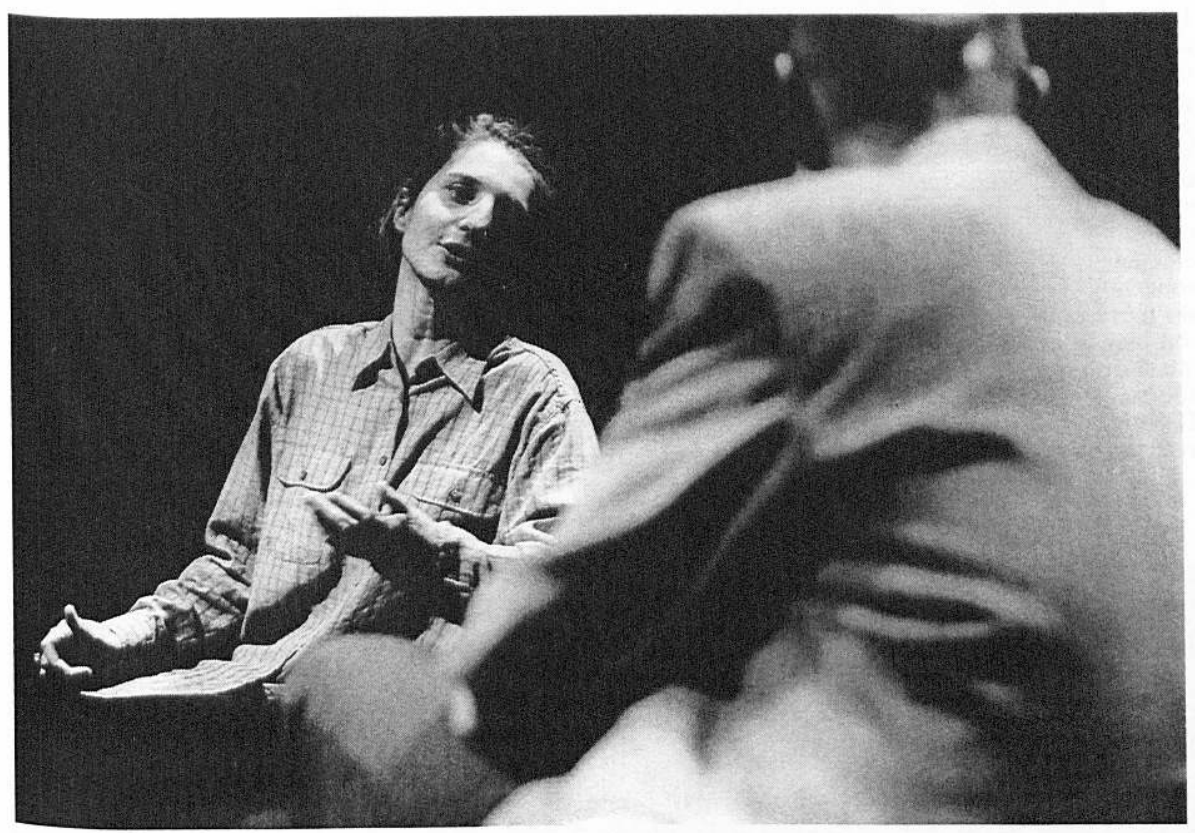

Photo Samuel Carnovalli

\section{NOTES}

1. Le texte est publié aux éditions Les Solitaires Intempestifs.

2. La pièce a été créée par la Compagnie Brozzoni au théâtre de Montbéliard, le 24 avril 1996. Voir Coulisses $n^{\circ} 14$. Elle est publiée chez Actes Sud-Papiers. 